\title{
Study on Total Amount Accounting of Pollutants Entering Qinghe River Basin
}

\author{
Han Zhuo ${ }^{1, a}$, Zhang Ji ${ }^{1}$ ， Su Jialiang ${ }^{1}$ ，Zheng Zhiyuan ${ }^{2} ，$ Lu Shuaiyu $^{3} ，$ Zhou Weiwei $^{4}$ ， and Fu Jinxiang ${ }^{3, b^{*}}$ \\ ${ }^{1}$ China Nuclear New Energy Investment CO.,Ltd., Shenyang, 100000, China \\ ${ }^{2}$ China Nuclear Fushun Environmental Technology Co.,Ltd, Shenyang, 113000, China \\ ${ }^{3}$ Shenyang Jianzhu University, Shenyang, 110000, China \\ ${ }^{4}$ Shandong Urban Construction Vocational College,Jinan,250103, China
}

\begin{abstract}
The calculation of the total amount of pollutants entering the river is the key to the total amount control system. Since non-point source pollution has not been monitored normally and effectively, based on the principle of the balance of input and output of pollutants, the 2009-2013 Qinghe water quality monitoring data, pollution source survey data and monitoring data were used to establish a binary statistics of the total amount of pollutants model. MATLAB software is used to solve the model. The results show that the model has strong data assimilation ability, can accurately calculate the monthly COD inflow into the river, can divide the point source and non-point source pollution load, and can meet the needs of actual research.
\end{abstract}

\section{Introduction}

In recent years, the prevention and control of water environmental pollution has changed from simple concentration control to total control, in which pollutant discharge and total pollutant monitoring are the key links of total control system. Accurate accounting of the load of pollutants entering the water body can judge and predict the current and future trends of water pollution, thus providing scientific basis for government decision-making and management. Provide data support for water resources protection and water pollution prevention.

A lot of models have been used to estimate the amount of non-point source pollutants entering the river, such as GLEAMS, AGNPS, SWAT [1, 2, 3, 4], but these models need more data parameters to be corrected, which seriously limits the effective application of these models outside the modeling area. At present, hydrological estimation method, output coefficient method, source strength coefficient method and so on are widely used model methods $[5,6,7]$. The required data are less and the operation is simple, but there is a large error in calculating the relative contribution rate of point source and non-point source pollution.

Facing the severity of water environment quality and the arduous task of total pollutant reduction, on the basis of the domestic and foreign research, combining the water environment characteristics and the pollution situation, choose the total monitoring index COD [10], by pollutant input - output balance principle , using the optimization solution function in MATLAB software, build a binary statistical model suitable for the total accounting of Qinghe basin, to provide technical support for the total accounting of pollutants in the Liaohe basin. This study

\footnotetext{
* Corresponding author: ${ }^{\mathrm{b}}$ 466755432@qq.com

a hanzhuo@zhxny.net.cn
}

can also divide the point source and the non-point source pollution load, estimate the amount of pollutants into the river, monitor the total amount of water pollutants in the Liaohe River Basin, and provide help for the performance evaluation of the total water pollutant reduction amount, the pollutant discharge declaration, and the implementation of the pollutant discharge permit .

\section{Materials and Methods}

\subsection{Overview of demonstration areas}

Qinghe River is the main stream of the east bank of Liaohe River system, which originates in Tiger Mountain, Yinge men Town, Qingyuan County. Drainage basin area is 4813.95km2. It mainly flows through Qinghe District, Kaiyuan City, Changwu County and Xifeng County under the jurisdiction of Tieling.

"Qinghe River Basin" as the "12th Five-Year Plan " water special key demonstration basin, the drainage system is developed and the tributaries are numerous. There are 106 pollution sources in the basin, only 15 pollution sources, the main stream of Qinghe River and 4 tributaries were routinely monitored. Based on water quality monitoring data for 2001-2010, the water quality of the main stream of Qinghe River is increasing from 2001 to 2005 , from 2006 to 2010 , the comprehensive pollution index showed no significant downward trend. 


\subsection{Research methods}

\subsubsection{Method of accounting for point source emissions and river flows}

Verification of total discharge amount of pollution sources. The accounting methods of the total amount of pollution source include material balance method, comparative analysis of relevant data and so on. According to the current situation of pollution source monitoring in watershed, the total amount of pollution discharge is verified by using the on-line concentration and flow monitoring data of pollution source, the monitoring data of pollution source and the general survey data of pollution source.

Verification of the total amount of pollutants entering rivers from pollution sources.Considering the process of entering the river of pollutants in different pollution sources, referring to the "Guiding Opinions on the Distribution of Major Water Pollutants Total" by the State Environmental Protection Administration and the technology of controlling the total amount of water pollutants in the river basin through the river inflow coefficient to establish a possible relationship between the amount of pollutants discharged and the amount of water entering the river.Point-source pollution in the study area into the river volume estimate see formula (1).

$$
Q_{\text {Into the river }}=Q \times A
$$

In formula:

QInto the river-The amount of point source into the $\operatorname{river}(\mathrm{t})$;

Q-Total point source discharge $(\mathrm{t})$;

A-Inflow coefficient.

\subsubsection{Non-point source pollutant discharge and river entry accounting methods.}

The principle of model construction. Taking "watershed scale" as the object, the total amount of pollutants entering the river is calculated. The i month pollutant load $\mathrm{Li}(\mathrm{t} /$ month) in Qingliao section of Qinghe basin is the final result of point source pollutant entry $\mathrm{Pi}(\mathrm{t} / \mathrm{month})$ and non-point source pollutant entry $\mathrm{Ni}(\mathrm{t} / \mathrm{month})$ and river retention process.

Considering that the amount of point source entering river is relatively stable during the study period, the amount of non-point source entering river is mainly affected by rainfall runoff process, and the Ri of pollutant retention factor is mainly related to flow rate and water temperature, etc., and the amount of pollutants entering the river simplify to formula (2).

$$
L i=\left(A+B Q_{i}^{c}\right) L i=\left(A+B Q_{i}^{c}\right) \exp \left(-D q_{i} t_{i}\right)
$$

In formula:

Li-Pollutant load in month $\mathrm{i}$;

A-The amount of point source pollutants entering the river;

B-Potential for river entry of non-point source pollutants;

$\mathrm{C}$ - The effect of river flow on the inflow of non-point source pollutants;

Qi-Average flow for the i month $\left(\mathrm{m}^{3} / \mathrm{s}\right)$;

Qi,ti-Represents river flow and water temperature variables, respectively;

D-Model coefficients.

The above parameters are dimensionless.

Model building method. This study uses the constrained minimal (nonlinear programming) solution function in the MATLAB optimization toolbox fmincon optimizes the four coefficients in A, B, C, D binary statistical model. When the control measures of point source and non-point source pollution have not changed significantly during the research period, the above four model coefficients can be considered as constants.

In order to reduce the influence of the absolute value of the solution error on the convergence efficiency, the natural logarithm is taken at the same time on the left and right sides of the formula before solving. An objective function $(\mathrm{O})$ is set as the average value of the absolute value of the error between the calculated value of the output load of pollutants in the outlet section and the calculated value of the simulated value. According to the monthly average output load, flow rate and water temperature of the outlet section during the research period, the model coefficients are not less than zero. The model system values under the minimum value of the objective function are obtained, such as formula (3).

$$
\operatorname{Min}(O)=\frac{\sum a b s\left[\operatorname{In}(\operatorname{Li})-\operatorname{In}\left(A+B Q_{i}^{c}+U_{i}-C_{i}\right)\right]+D q_{i} t_{i}}{n}
$$

Model check coefficient. Formula (4) Nash efficiency coefficient (NSE) is model check coefficient.

$$
N E S=1-\frac{\sum_{i=1}^{n}\left(O b s_{i}-S_{i} m_{i}\right)^{2}}{\sum_{i=1}^{n}\left(O b s_{i}-\overline{O b s}\right)^{2}}
$$

In formula:

$\mathrm{Obs}_{\mathrm{i}}$ - Measured value at i monitoring point ( $\mathrm{t} /$ month);

$\mathrm{S}_{\mathrm{i}} \mathrm{m}_{\mathrm{i}}$ - Simulation values corresponding to the $\mathrm{i}$ monitoring point ( $\mathrm{t} / \mathrm{months})$;

Obs-Measured average with i monitoring point $(t /$ month).

\section{Results and discussion}

\subsection{Point source pollutant discharge and the calculation of the quantity into the river}

Emissions accounting. Twenty pollution sources in the Qinghe River Basin were discharged directly into the river, including 16 industrial pollution sources and 4 sewage treatment plants. The annual COD emissions are 1236.77 $\mathrm{t} / \mathrm{n}$, based on pollution source survey data and environmental monitoring data.

Accounting for Contaminants Entering the River. The Google Earth software is used to calculate the distance from the sewage outlet of 20 pollution sources to the estuary. Determine the point source entry coefficient according to Table 1. 
Table1. Reference value of river inflow coefficient corrected by point source distanc

\begin{tabular}{|c|c|}
\hline Ariver inflow coefficient & Reference value \\
\hline $\mathrm{L} \leq 1 \mathrm{~km}$ & 1.0 \\
\hline $1 \mathrm{~km}<\mathrm{L} \leq 10 \mathrm{~km}$ & 0.9 \\
\hline $10 \mathrm{~km}<\mathrm{L} \leq 20 \mathrm{~km}$ & 0.8 \\
\hline $20 \mathrm{~km}<\mathrm{L} \leq 40 \mathrm{~km}$ & 0.7 \\
\hline $\mathrm{L}>40 \mathrm{~km}$ & 0.6 \\
\hline
\end{tabular}

The results show that the distance into the river is usually short, the coefficient of entering the river is generally $0.9 \sim 1.0$, and the difference between the discharge of pollutants and the amount of entering the river is small. The COD volume of 20 pollution sources in Qinghe basin is estimated to be $730.8 \mathrm{t} / \mathrm{n}$.

\subsection{Pollution Load Analysis of Qinghe Basin}

A total of four-year flow, water temperature and concentration monitoring data were used in 2009, 2010, 2012 and 2013. According to the monthly pollutant load of river, the monthly average COD load of monitoring section is calculated. The results are shown in Table 2 .

Table2. Annual monitoring section COD monthly flow and load

\begin{tabular}{|c|c|c|}
\hline Time & Annual flows $\left(\mathrm{m}^{3} / \mathrm{s}\right)$ & COD load $(\mathrm{t} /$ months $)$ \\
\hline 2009 & 22.55 & 982.88 \\
\hline 2010 & 64.55 & 3144.12 \\
\hline 2012 & 27.59 & 748.09 \\
\hline 2013 & 69.31 & 2696.55 \\
\hline
\end{tabular}

Because of the freezing period in the north, 12 months are divided into three water periods, namely, dry season, high season and peacetime period. Because the non-point source pollution is mainly caused by the runoff produced by rainfall and the rainfall is very small in the dry season, the influence of the dry season is not considered when calculating the amount of non-point source water pollutants entering the river in the basin, and only the point source into the river is calculated in the dry season. The annual average flow and pollution load are calculated by excluding the flow and pollution load in 1, 2, 3, 4 and December of the dry season. The results are shown in Table 3.

Table3. Average annual flow and monthly COD load of section

\begin{tabular}{|c|c|c|}
\hline Time & Annual flows $\left(\mathrm{m}^{3} / \mathrm{s}\right)$ & COD load ( $\mathrm{t} /$ months $)$ \\
\hline 2009 & 33.43 & 1181.22 \\
\hline 2010 & 102.07 & 4862.27 \\
\hline 2012 & 50.44 & 1252.63 \\
\hline 2013 & 93.9 & 3818.81 \\
\hline
\end{tabular}

\subsection{Approved river intake of non-point source pollutants}

It can be seen from tables 1 and 2 that the average annual flow in 2010 and 2013 is similar and can be used as a calculation series; the monitoring data for 2009 and 2012 are used as a comparison series to verify the calculation results.

\subsubsection{Model calibration}

The load quantity, flow rate and water temperature data of qingliao monitoring section COD demonstration area month by month in 2010 and 2013 are used. According to formula (3), the optimal solution under nonlinear equality constraints is solved in MATLAB software, the coefficient A, B, C, D in binary statistical model is corrected, and then the monthly monitoring data in 2009 and 2012 are used to verify. The results are shown in Table 4 and Table 5.

Table4. Model coefficient correction model coefficient of Qinghe River Basin

\begin{tabular}{|c|c|c|c|}
\hline $\mathrm{A}$ & $\mathrm{B}$ & $\mathrm{C}$ & $\mathrm{D}$ \\
\hline 115.0443 & 30.0443 & 1.0543 & 0.6443 \\
\hline
\end{tabular}

Table5. Annual COD inflow from various sources in Qinghe River Basin

\begin{tabular}{|c|c|c|}
\hline \multicolumn{3}{|c|}{ COD river intake (t/ years) } \\
\hline Time & Point source & Non-point ource \\
\hline 2009 & 805.31 & 8777.6125 \\
\hline 2010 & 805.31 & 28157.1535 \\
\hline 2012 & 575.22 & 9587.7957 \\
\hline 2013 & 805.31 & 26750.7605 \\
\hline
\end{tabular}

Note: Water quality data are missing from August to September 2012 , and the period of high and flat water is calculated according to 5 months. Other years are based on 7 months.

At the same time, through the verification of the COD load at the end of the monitoring section of the Qinghe River Basin, from Figure 1, it can be obtained that the COD simulation value of the monitoring section is basically close to the measured value of the load.

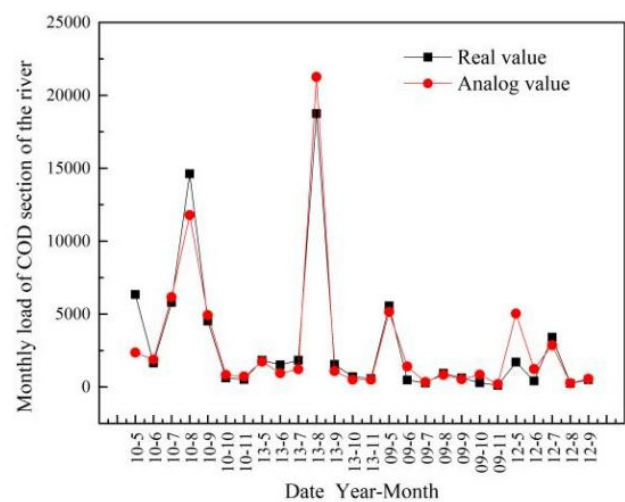

Fig 1. Analysis of COD load simulation at the end of each monthly river section

Calculating the Nash coefficient by the measured and simulated values of the COD load of the outlet section of 
Qinghe River Basin in 2010 and 2013, The results show that the Nash-Sutcliffe coefficient $=0.9284>0.65$, relative error is $<7.16 \%$. Referring to the general evaluation of the application results of SWAT, AGNPS, HSPF and other computational models, When the coefficient of the monthly COD load simulation results $>0.65$, The model results are quite satisfactory. Using data from 2009 and 2012 to validate the model, After verification, the calculated coefficient is $0.7893>0.65$.

So according to Figure 1 and calculation of Nash coefficient, a statistical model established in this study can accurately calculate the monthly COD inflow, the test results can meet the needs of practical research.

\subsubsection{Analysis of Model Results}

Analysis of the contribution rate COD point source and non-point source. The total amount of COD entering the river in the Qinghe River Basin from 2009 to 2013 was $2933.25 \mathrm{t} / \mathrm{month}$, and the total amount of point source COD entering the river in high water period and peacetime was $115.04 \mathrm{t} /$ month, accounting for $3.9 \%$ of the total amount of entering the river in COD month. Judging from Figure 2, the contribution rate of point source pollutants into the river decreases significantly with the increase of river flow. Under the condition that the average monthly discharge of the river $<6 \mathrm{~m}^{3} / \mathrm{s}$, the contribution rate of point source pollution $>30$. It is still necessary to control point source in dry season.

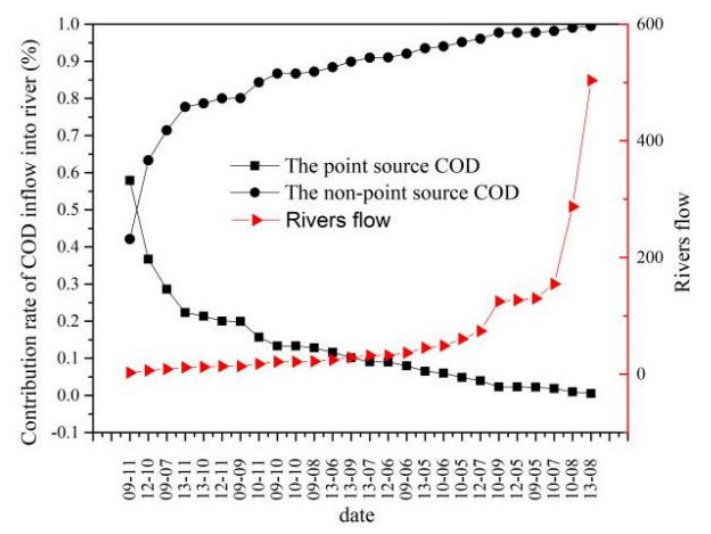

Fig 2. Variation trend of contribution rate of COD inflow from point source and non-point source

Analysis of point source COD inflow. The monitoring results of 20 pollution sources in the Qinghe River Basin show that the average annual inflow COD the monitored sources is $60.9 \mathrm{t} /$ months, and the model calculation is much larger than that of the field monitoring COD. This may be due to the existence of pollution source overdischarge and direct discharge of domestic sewage in actual production. Therefore, the binary statistical model established in this study can effectively help the regulatory authorities to identify the possible phenomena of pollution source overstepping and stealing, and promote the monitoring of point source pollution.

Analysis of COD inflow of non-point source. The average monthly inflow COD non-point sources in Qinghe basin is $2818.2047 \mathrm{t}$, accounting for $96.1 \%$ of the total inflow of COD in Qinghe basin. It is consistent with the results that the Qinghe River basin in the demonstration area is mainly polluted by non-point sources.

\section{Conclusion}

(1)In view of the incomplete data of Qinghe River Basin, and based on the characteristics of cold regions in northern my country, MATLAB is used to optimize the solving function to construct a binary statistical model suitable for accounting.

(2)The contribution rate of non-point source pollution in the basin during normal and high water periods was $96.1 \%$, and that of point sources was $3.9 \%$.

(3)The contribution rate of non-point source pollution increases with the increase of flow rate. Under the condition that the average monthly discharge of river is $<6$ $\mathrm{m}^{3} / \mathrm{s}$, the contribution rate of point source pollution is $>30 \%$. Therefore, it is still necessary to control point source in dry season.

\section{Acknowledgments}

This study was supported by the Research and application on the baseline level of environmental damage of national key research and development project. (2018YFC1801203-02 )

\section{References}

1. Hao F.H., Yang S.T., Cheng H.G., etc. (2006) Calculation method of non-point source pollution load in large-scale area. Journal of Environmental Science, 3: 375-383.

2. Zheng H.Q., Pan W.B. (2011) Study on the Pollution Load of Minjiang River in Fuzhou Section. Journal of Subtropical Resources and Environment, 6: 24-30

3. Zhao Y.Q., Li W.C., Pu H.H., etc. (2021) Identification and analysis of non-point source nitrogen in Laoguan River Watershed based on ArcSWAT. Journal of Water Ecology, 1-16.

4. Nie R., Li G.Q., Zhuge Y.S., etc. (2021) Analysis on the contribution rate of regional pollution in Gangnan - Huangbizhuang Reservoirs. Journal of Water Ecology,1-17.

5. Chen D.J., Sun S.Y., Jia Y.N. (2013) Bivariate Statistical Model for Calculating Phosphorus Input Loads to the River from Point andNonpoint Sources. Environmental Science, 34: 84-90.

6. Chen Y.Y., Hui E.Q., Jin C.J., etc. (2003) A Hydrological Method for Estimation of Non-Point SourcePollution Loads and Its Application. Environment Engineering, 16: 10-13.

7. You K., Wang D., Fu J.X., etc. (2014) Building of Monitoring Index System of Pollution Sources In Puhe Basin. Environment Engineering, 33: 122-125. 